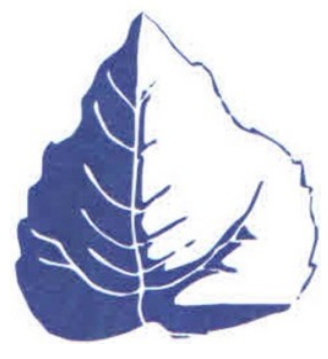

УДК 631.795.5

\section{МЕЛИОРАЦИЯ, РЕКУЛЬТИВАЦИЯ И ОХРАНА ЗЕМЕЛЬ MELIORATION, RECULTIVIATION AND LAND PROTECTION}

https://doi.org/10.23947/2413-1474-2020-4-2-80-89

Фотограмметрические и дистанционные методы создания и обновления топографических карт

Овчинникова Н. Г., Бутова А. Ю.

Донской государственный технический университет, г. Ростов-на-Дону, Российская Федерация

Рассматриваются автоматизированные методы создания и обновления картографической основы. Отмечается, что процесс разработки топографических карт напрямую связан с ведением Единого государственного реестра недвижимости. Также приводится ряд преимуществ использования автоматизированных методов создания карт по сравнению с аналоговым, даются описания работ. Раскрыты особенности и преимущества использования фотограмметрических технологий при разработке картографического материала. Приведены основные методы и этапы аэрофотосъёмки. Перечислены основные цели и задачи создания картографической основы кадастра. Сделаны основные выводы о влиянии точности картографических материалов на процесс ведения Единого государственного реестра недвижимости.

Ключевые слова: картографическая основа, Единый государственный реестр недвижимости, фотограмметрия, дистанционное зондирование, аэрофотосъёмка, цифровой снимок, топографическая карта.

Образец для цитирования: Овчинникова, Н. Г. Фотограмметрические и дистанционные методы создания и обновления топографических карт / Н. Г. Овчинникова, А. Ю. Бутова // Экономика и экология территориальных образований. — 2020. — Т.4, № 2. - С. 80-89. https://doi.org/10.23947/2413-14742020-4-2-80-89

\title{
Photogrammetric and distance methods for creating and updating of topographic maps
}

Ovchinnikova N. G., Butova A. Y.

Don State Technical University, Rostov-on-Don, Russian Federation

The article discusses the automated methods for creating and updating the cartographic basis. It is noted that the process of developing topographic maps is directly related to the maintenance of the Unified State Register of Real Estate. The article also gives a number of advantages of using automated methods of creating maps over analog ones and describes the work. The features and advantages of using photogrammetric technologies in the development of cartographic material are described. The main methods and stages of aerial photography are presented. The main goals and objectives of creating the cartographic basis of the inventory are listed. The main conclusions are made about the influence of the accuracy of cartographic materials on the process of maintaining the Unified State Register of Real Estate.

Key words: cartographic basis, the Unified State Register of Real Estate, photogrammetry, remote sensing, aerial photography, digital photography, topographic map. 
For citation: Ovchinnikova, N. G., Butova A. Y. Photogrammetric and distance methods for creating and updating of topographic maps. Economy and ecology of territorial formations, 2020, vol. 4, no 2, pp. 80-89. https://doi.org/10.23947/2413-1474-2020-4-2-80-89

Введение. Ведение Единого государственного реестра недвижимости (ЕГРН) напрямую связано с осуществлением картографирования местности. Высокоточная картография служит основой для получения достоверных сведений при описании границ объектов недвижимости.

С развитием и усложнением земельных отношений создание единой картографической основы приобретает приоритетное направление. Цель данной работы - проанализировать преимущества использования автоматизированных методов создания карт перед аналоговым, выявить особенности и преимущества использования фотограмметрических технологий при разработке картографического материала.

Основная часть. В современном мире всеобщая цифровизация не обошла стороной такую важную отрасль, как разработка картографического материала. Начиная с 90-х годов прошлого столетия в нашей стране начали внедрять методы цифровой фотограмметрии в производство и обновление цифровых карт и планов, а также в иные сферы применения аэрокосмических материалов [1-2].

Цифровые методы производства картографических материалов в отличие от методов, применяемых ранее, позволили автоматизировать огромный перечень трудоёмких процессов при разработке и обновлении цифровых топографических карт [3]. Данные методы имеют ряд преимуществ, которые представлены на рис. 1.
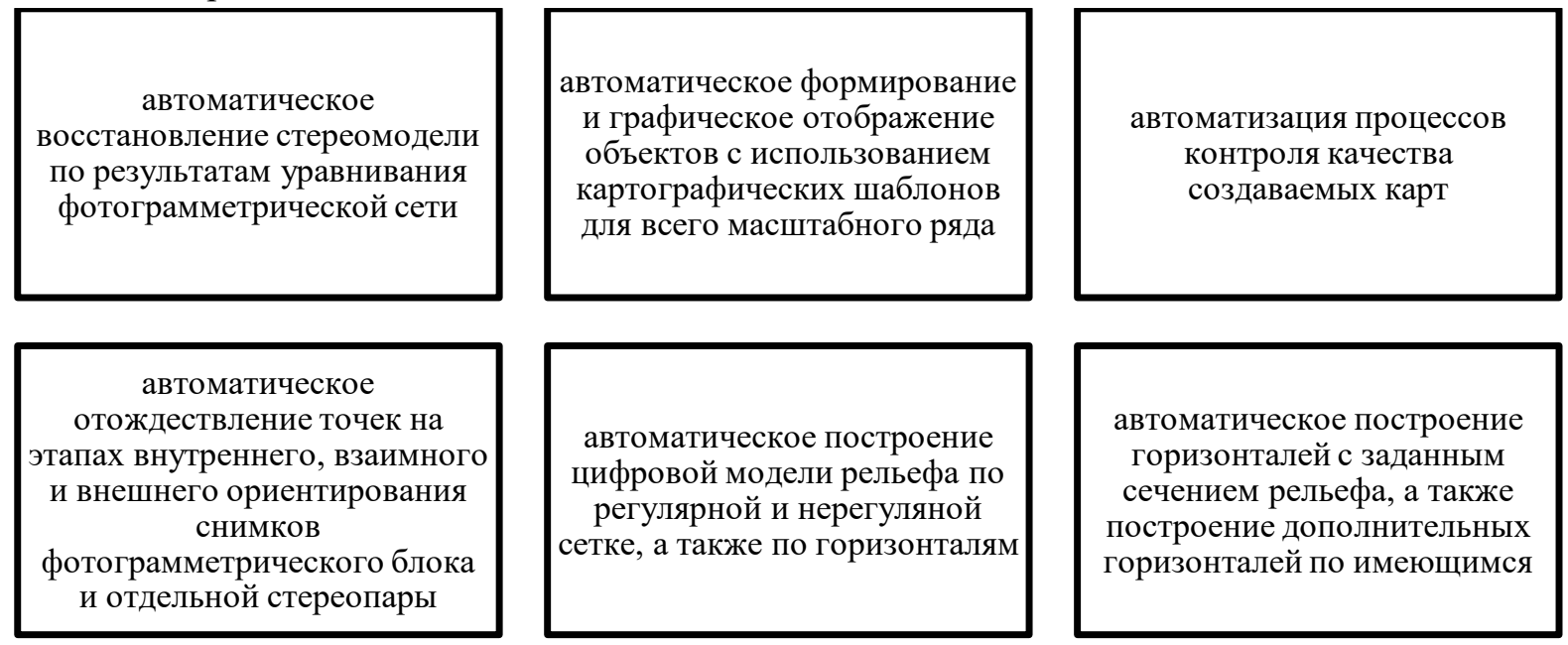

автоматическое построение горизонталей с заданным сечением рельефа, а также построение дополнительных горизонталей по имеющимся

автоматическое создание ортофотоизображения на блок

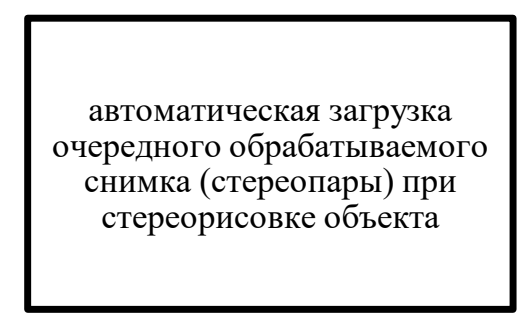

автоматическая загрузка чередного обрабатываемого снимка (стереопары) пр стереорисовке объекта стереоскопический сбор контуров и пикетов в режиме автоматического стерео отождествления

Рис. 1. Преимущества цифровых методов производства картографических материалов

Применение методов фотограмметрического сгущения съёмочного обоснования позволяет выполнять цифровую фототриангуляцию в режиме реального времени, что обеспечивает быстрое устранение возможных ошибок измерения.

В наши дни области применения фотограмметрических технологий при создании топографических карт весьма обширны [4]. Применяя данные методы, можно установить такие характеристики пространственного объекта, как форму, размеры, площадь и положение в пространстве, по снимкам. Преимущества фотограмметрической обработки представлены на рис. 2. 


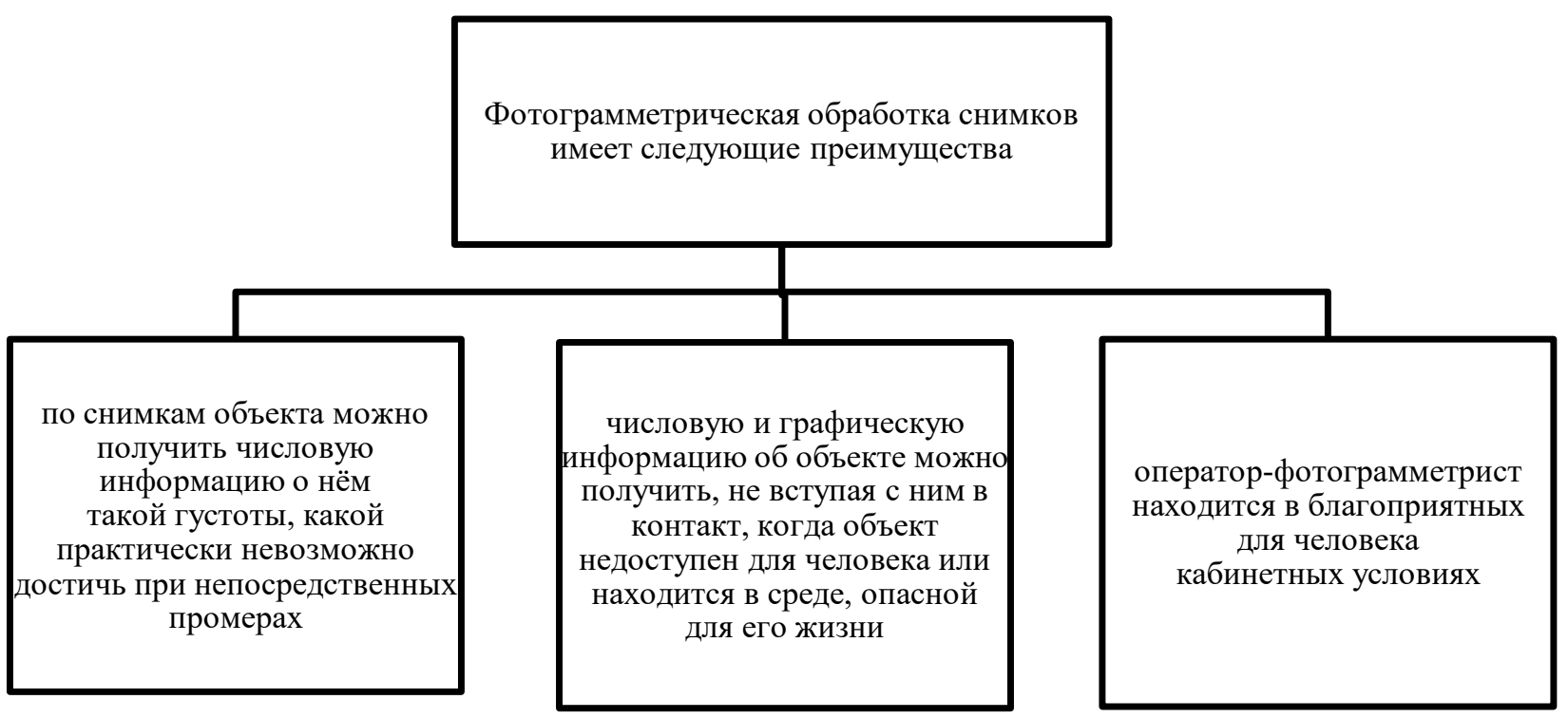

Рис. 2. Преимущества фотограмметрической обработки снимков

Направлением, напрямую связанным с развитием фотограмметрии, является разработка карт и планов по готовым снимкам [5-6].

Фотограмметрические работы - важнейшая часть создания и обновления цифрового картографического материала.

Особенности фотограмметрического метода создания цифровых топографических карт представлены на рис. 3.

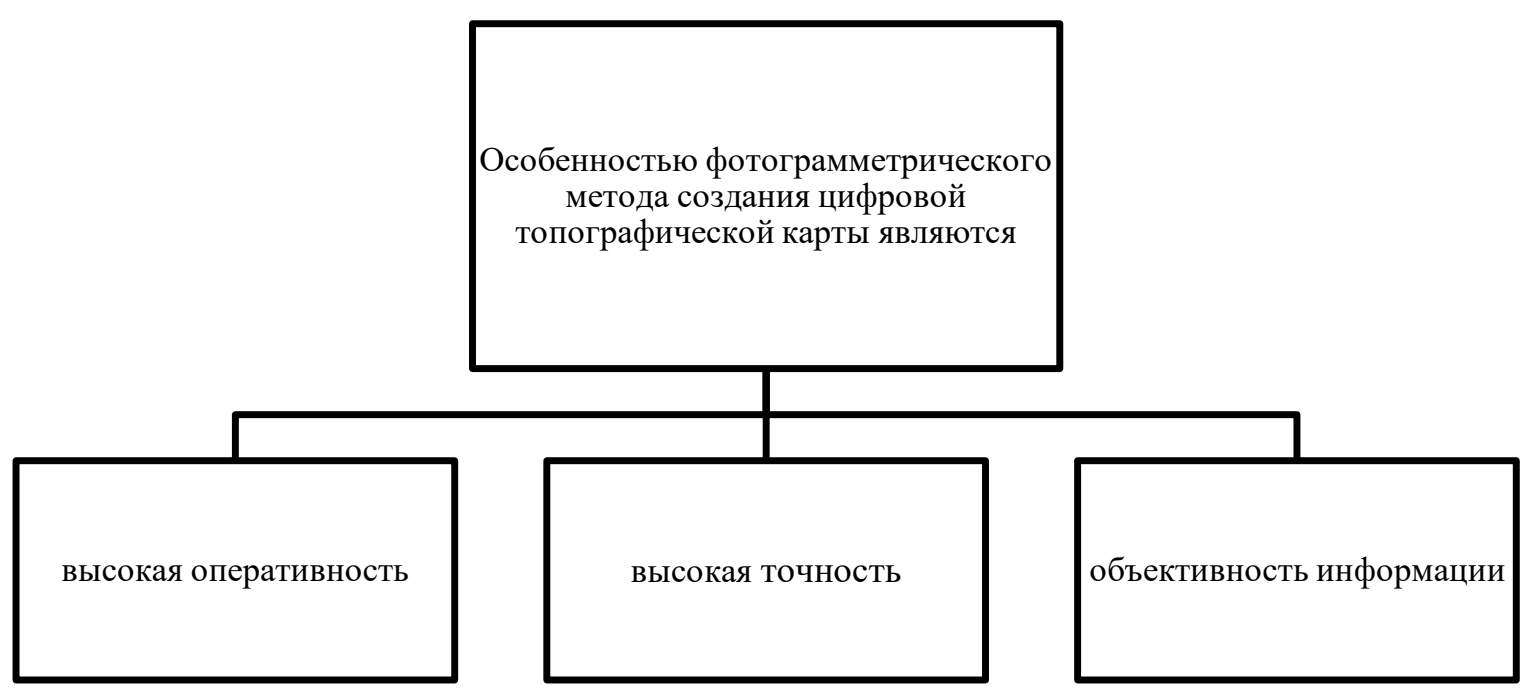

Рис. 3. Особенности фотограмметрического метода создания цифровых топографических карт

С ростом технического прогресса начали появляться усовершенствованные методы обработки аэрокосмической информации, позволяющие автоматизировать большую часть фотограмметрической обработки информации [7].

Цифровой снимок - это уникальный способ записи определённых данных об объекте. Он имеет ряд преимуществ перед фотоизображением [8-9].

Создание цифровых топографических карт фотограмметрическими методами съёмки включает в себя ряд камеральных работ, представленных на рис. 4. 

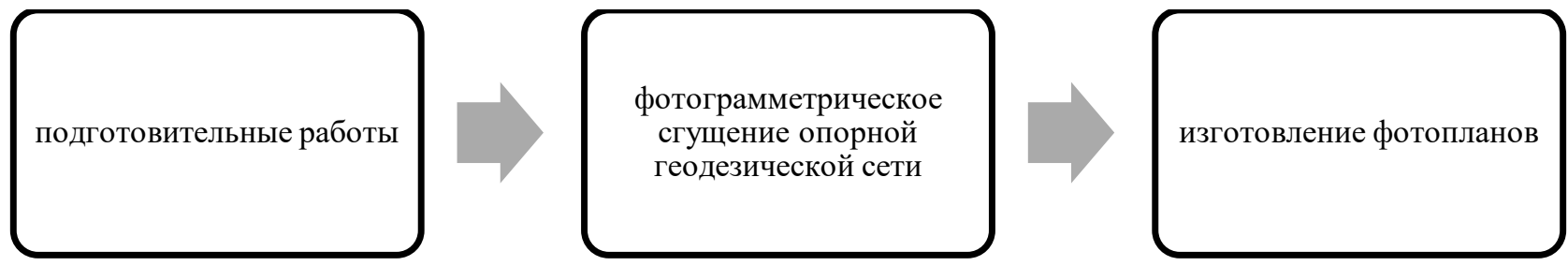

сбор информации о контурах по фотоплану, одиночным снимкам или стереопарам
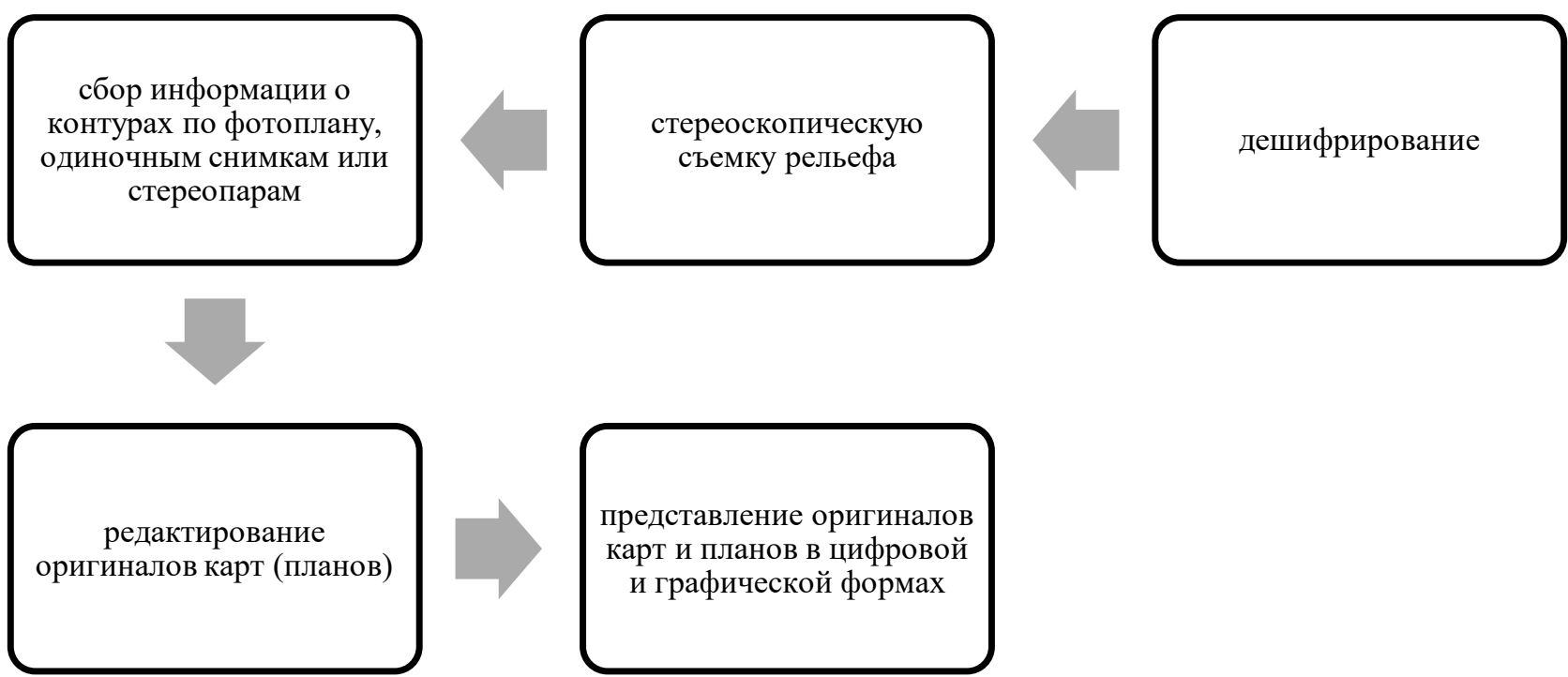

Рис. 4. Камеральные работы при создании цифровых топографических карт фотограмметрическим методом

Главной целью обработки снимков выступает получение качественных и геометрических характеристик объекта [10-12].

В свою очередь, снимки получают в результате осуществления аэрофотосъёмки, состоящей из этапов, представленных на рис. 5.
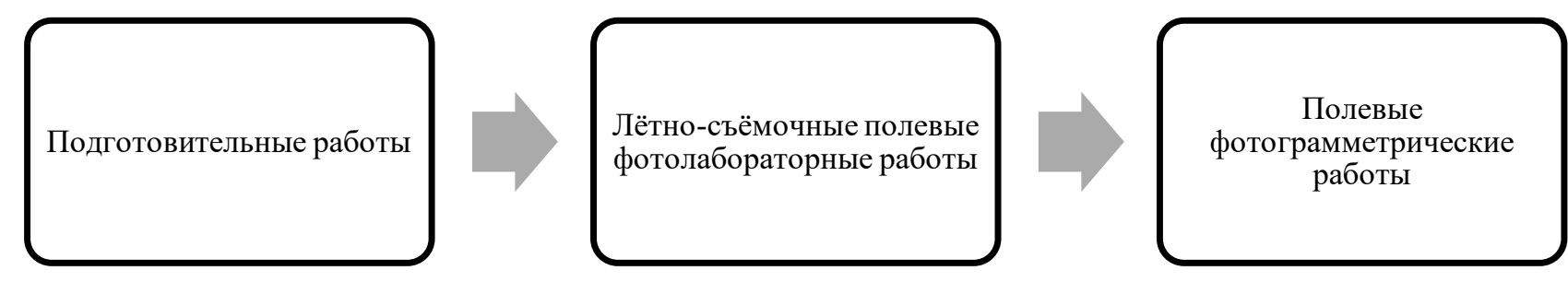

Рис. 5. Этапы аэрофотосъёмки

Объектом данных работ выступает определённая территория местности [13-15].

Помимо аэрофотосъёмки, в процессе создания топографических карт может задействоваться космическая съёмка территории.

Применение дистанционных методов зондирования земной поверхности даёт возможность охватить большие по площади территориальные единицы и получить всю необходимую информацию обо всех объектах, находящихся на них. Наличие современных аппаратно-программных комплексов позволяет осуществлять высокоточные измерения по полученным данным [16-17]. 
Распространённая в наши дни цифровая аэрофотосъёмка производится при помощи современных топографических аэрофотосъёмочных систем. Данные системы обладают высокой производительностью, по сравнению с предшествующими [18]. Помимо этого, современные системы отличаются точностью, разрешением и фотометрическим качеством изображения.

Преимущества цифровой аэрофотосъёмки перед аналоговой представлены на рис. 6.

отсутствие процессов

фотохимической обработки и необходимости в фотолаборатории

отсутствие деформации фотоматериала и связанных с ней геометрических искажений аэрофотоснимков отсутствие необходимости внутреннего ориентирования снимков по координатным меткам при фотограмметрической обработке отсутствие процесса сканирования аэрофотоснимков более высокое фотометрическое качество: проработка деталей в глубоких тенях
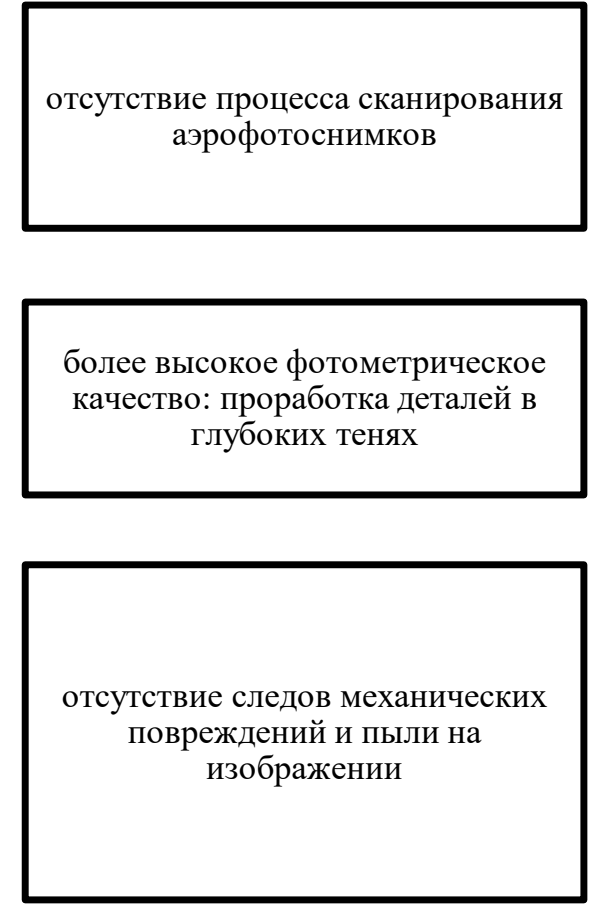

Рис. 6. Преимущества цифровой аэросъёмки перед аналоговой

Ещё одним преимуществом цифровой аэрофотосъёмки является невероятно высокая производительность. При благоприятных условиях производительность может достигать 500-600 километров за один съёмочный день при съёмке линейных объектов, а также 500-1000 квадратных километров при съёмке площадных объектов [19].

В наши дни применяют способы создания цифровой основы для построения топографических карт, представленные на рис. 7.

По исходным картографическим материалам

• Сканируются ДПХ (диапозитивы постоянного хранения, с которых на картографических фабриках изготавливают печатные формы) с разрешением порядка 800 dpi (количество точек на дюйм), и далее по растровым изображениям создается цифровая карта. Эта технология хороша тем, что можно векторизовать более половины содержания карты в автоматическом режиме, т. к. ДПХ - это расчлененные по содержанию карты (рельеф, гидрография, заливки леса и гидрографии, контур) и совмещенные. Технология приемлема для средних масштабов $(1: 10000-1: 1000000)$.

По материалам наземных съемок: тахеометрическая съемка, иногда даже мензульная

• Это, как правило, небольшие участки съемок. Иногда бывает целесообразно выполнить съемку небольшого закрытого участка местности полевым способом, и тогда на сканере, позволяющем сканировать

картографические материалы на жесткой основе, сканировать материалы наземной съемки, привязывать и векторизировать растры

Стереотопографический метод

• Карта создается с нуля, равно как и её актуализация (обновление), что означает минимум полевых работ, максимум работ камеральных, что удешевляет и сокращает цикл создания топографической карты

Рис. 7. Способы создания цифровой основы для топографических карт 
После непосредственного осуществления съёмки настаёт период постобработки полученной информации, этапы которого представлены на рис. 8.

построение мозаики («накидного»

монтажа) изображений;

формирование «лёгкой»

стереомодели оперативного

дешифрирования состояния местности

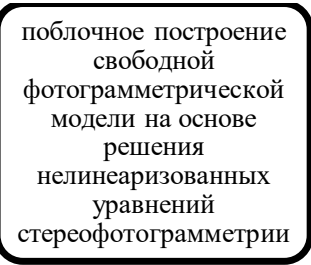

стереофотограмметрии

построение цифровой модели рельефа

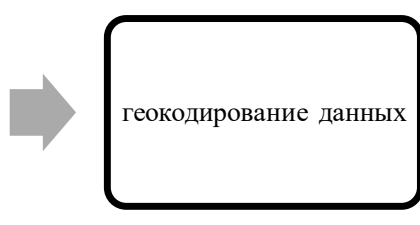

покадровое определение значений элементов внешнего ориентирования

создание и наполнение

векторных слоев

Рис. 8. Этапы постобработки данных аэрофотосъёмки

Цифровая аэрофотосъёмка, методика и преимущества которой описаны ранее, применяется для решения задач, представленных на рис. 9.
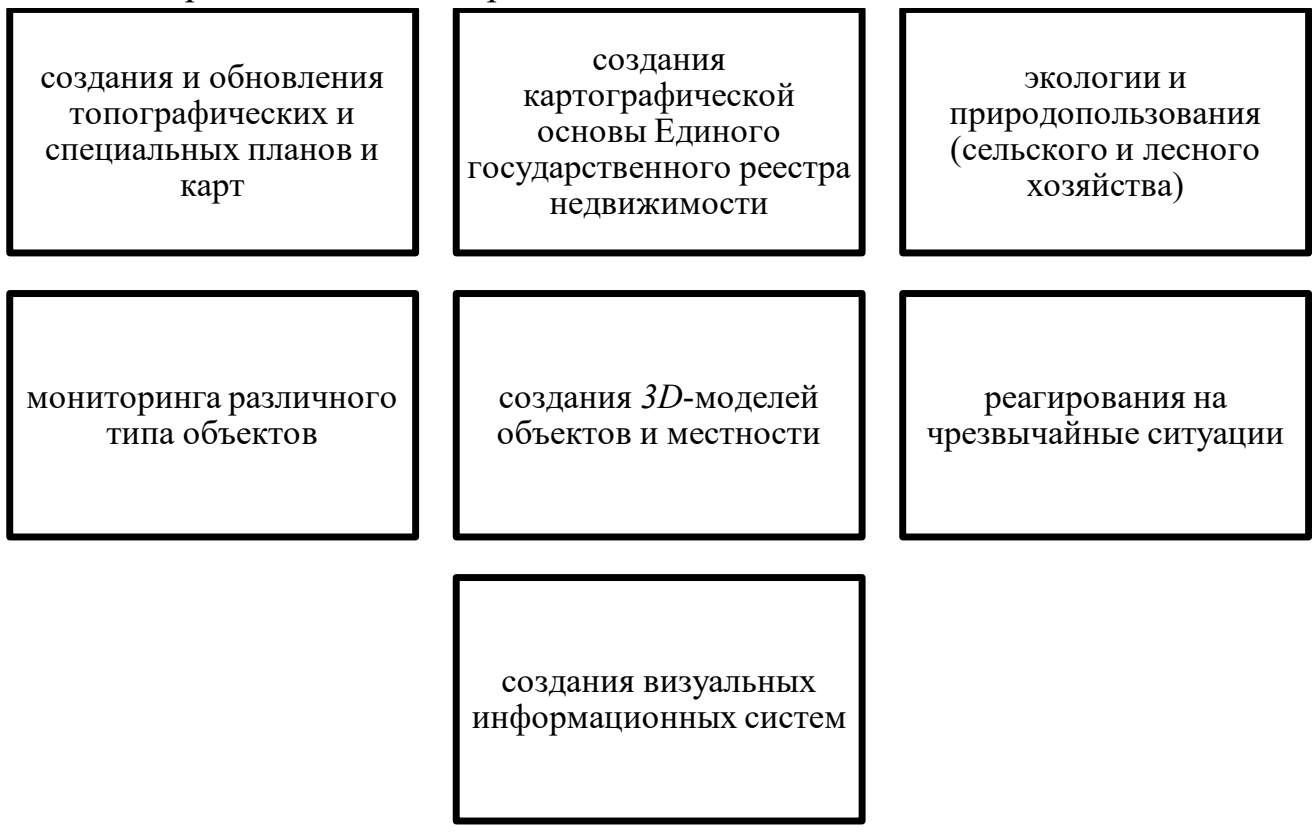

Рис. 9. Задачи аэрофотосъёмки

Как упоминалось ранее, важную роль создание топографических карт играет в кадастровой деятельности. Цели и задачи создания картографической основы кадастра представлены на рис. 10. 
Направления и задачи применения

Инвентаризация земель

$$
\begin{aligned}
& \text { Осуществление кадастрового деления территории и проведение его } \\
& \text { корректировок }
\end{aligned}
$$

Составление и ведение кадастровых карт

Определение (уточнение) местоположения и координат характерных точек объектов недвижимости

Описание местоположения границ объектов землеустройства

Осуществление государственного земельного надзора

Сбор сведений о значениях факторов стоимости земельных участков в составе земель населённых пунктов

Рис. 10. Цели и задачи создания картографической основы кадастра

В соответствии с Федеральным законом от 13.07.2015 № 218-Ф3, под картографической основой Единого государственного реестра недвижимости понимают единую электронную картографическую основу. Данная основа служит для определения границ земельных участков и, как следствие, для вычисления их площадей. Для выполнения данных действий регламентирована определённая точность, так как площадь земельного участка напрямую связана с конечной стоимостью [20].

Точность определения координат поворотных точек границ земельных участков может повышаться за счёт использования современных технологий и методов создания картографической основы.

Картографические данные являются той основой, на которой строится Единый государственный реестр недвижимости. Поэтому важную роль здесь играет качество картографического материала.

В случаях отсутствия планово-картографического материала могут использоваться материалы аэрофотосъёмки и, в частности, ортофотопланы.

Как неоднократно отмечалось ранее, материалы аэрофотосъёмки отличаются большой точностью и объективностью отображения существующей ситуации на местности. Помимо этого, к преимуществам данного вида съёмки можно отнести возможность постоянных наблюдений за исследуемой территорией.

При помощи оптимального сочетания современных методов и технологий съёмки с последними достижениями фотограмметрии может быть достигнута максимальная эффективность ведения Единого государственного реестра недвижимости.

Заключение. На основании вышеизложенного можно сделать вывод о том, что картографическая информация, необходимая для ведения Единого государственного реестра недвижимости, требует постоянной актуализации и обновления. В современных условиях данные процессы необходимо осуществлять в сжатые временные сроки, что позволяют сделать дистанционные и фотограмметрические методы создания картографического материала.

\section{Библиографический список}

1. О государственной регистрации недвижимости: федер. закон [принят Государственной Думой 3 июля 2015 года, одобрен Советом Федерации 8 июля 2015 года] : [Электронный ресурс] / КонсультантПлюс. - Режим доступа: http://www.consultant.ru/document/cons_doc_LAW_182661/ (дата обращения: 02.03.2020). 
2. Аврунев, Е. И. Проблемы кадастровой деятельности / Е.И.Аврунев, А. И. Каленицкий, В. Н. Клюшниченко // Известия вузов. Геодезия и аэрофотосъемка. — 2015. — № 5S. - С. 99-103.

3. Гук, А. П. Принципы фотограмметрической обработки метрической информации, получаемой по аэрокосмическим снимкам / А. П. Гук // Гео-Сибирь. - 2006. - Т. 3, № 2. - С. 210-215.

4. Гук, А. П. Современное состояние и перспективное развитие фотограмметрических технологий, дистанционных методов и мониторинга по аэрокосмической информации / А. П. Гук, И. Т. Антипов // Гео-Сибирь. - 2005. - Т 5. - № 3. - С. 3-5.

5. Злобин, В. К. Обработка аэрокосмических изображений: монография / В. К. Злобин, В. В. Еремеев. - Москва : Физматлит, 2006. - С. 56-60.

6. Макриденко, Л. А. Дистанционное зондирование Земли из космоса и устойчивое развитие общества / Л. А. Макриденко, С. А. Золотой // Вопросы электромеханики. Труды ВНИИЭМ. - 2008. - T. 105. - C. 4-5.

7. Карпик, А. П. Разработка методики качественной и количественной оценки кадастровой информации / А. П. Карпик, Ю. А. Новоселов, А. В. Рычкова // Известия высших учебных заведений. Геодезия и аэрофотосъёмка. — 2013. - № S4. — С. 137-142.

8. Карпик, А. П. Анализ состояния и проблемы геоинформационного обеспечения территорий / А. П. Карпик // Известия высших учебных заведений. Геодезия и аэрофотосъемка. — 2014. — № S4. - C. 3-7.

9. Космические аппараты с оптико-электронными системами ДЗ3 // Геоматика. — 2009. — № 1. - C. 84-92.

10. Кузнецов, С. В. К вопросу о техническом регулировании в сфере геодезии, картографии и пространственных данных / С. В. Кузнецов, В. 3. Усатин // Геопрофи. - 2017. - № 6. - С. 12-16.

11. Лабутина, И. А. Дешифрирование аэрокосмических снимков: учебное пособие для студентов вузов, обуч. по спец. «География» / И. А. Лабутина. - Москва : Аспект Пресс, 2004. - С. 62-66.

12. Лисицкий, Д. В. Основные принципы цифрового картографирования местности / Д. В. Лисицкий. - Москва : Недра, 1988. — 259 с.

13. Пархоменко, И. В. Информационная модель государственного земельного надзора / И. В. Пархоменко // Известия высших учебных заведений. Геодезия и аэрофотосъемка. - 2015. № S5. - С. 90-96.

14. Овчинникова, Н. Г. Учетно-регистрационный процесс в системе управления земельными ресурсами / Н. Г. Овчинникова, Е. С. Шумкова // Экономика и экология территориальных образований. - 2016. - № 2. - С. 125-129.

15. Русских, А. В. Значимость документов территориального планирования муниципального образования для ведения ЕГРН / А. В. Русских, Е. Г. Овчинникова // Электронный сетевой политематический журнал «Научные труды Куб ГТУ». — 2017. — № 4. - С. 285-289.

16. Сапельников, С. А. Кадастровые карты муниципальных образований: баланс возможностей и потребностей / С. А. Сапельников, А. М. Тарарин, А. В. Андреев // Информационный бюллетень ГИС-Ассоциации. — 2010. — № 4 (76). — С. 17-23.

17. Судариков, В. Н. Основы аэрокосмофотосъёмки : учебное пособие / В. Н. Судариков, О. Н. Калинина. - Оренбург : ОГУ, 2013. - 191 с.

18. Тарарин, А. М. Развитие федерального картографо-геодезического фонда как элемента инфраструктуры пространственных данных / А. М. Тарарин, А. В. Ребрий // Великие реки 2016 : тез. докл. научн.-техн. конф. - Нижний Новгород, 2016. — С. 369-372.

19. Тарарин, А. М. Нормативно-правовые и концептуальные аспекты формирования кадастровых карт / А. М. Тарарин, Е. Г. Тарарина // Информационный бюллетень ГИС-Ассоциации. — 2010. — № 4. - C. 14-16.

20. Тарарин, А. М. Картографическая основа кадастра: история создания, цели и требования / А. М. Тарарин // Вестник СГУГиТ. - 2017. — Том 22, № 1. — С. 132-141. 
Поступила в редакцию 23.04.2020

Запланирована в номер 15.05.2020

\section{Oб авторах:}

Овчинникова Наталья Геннадьевна, доцент кафедры «Экономика природопользования и кадастра» Донского государственного технического университета (344000, РФ, г. Ростов-на-Дону, пл. Гагарина, 1), кандидат экономических наук, доцент, donong160875@yandex.ru

Бутова Анастасия Юрьевна, магистрант кафедры «Экономика природопользования и кадастра» Донского государственного технического университета (344000, РФ, г. Ростов-на-Дону, пл. Гагарина, 1), 1chinaski1@gmail.com

\section{References}

1. O gosudarstvennoj registracii nedvizhimosti: feder. zakon [prinyat Gosudarstvennoj Dumoj 3 iyulya 2015 goda, odobren Sovetom Federacii 8 iyulya 2015 goda]. On state registration of real estate: federal. law [adopted by the State Duma on July 3, 2015, approved by the Federation Council on July 8, 2015]. Consultant Plus. (In Russ.)

2. Avrunev EI., Kalenitsky AI., Klyushnichenko VN. (2015). Problemy kadastrovoj deyatel'nosti [Problems of cadastral activity]. University news. Geodesy and Aerophotography,2015; 5: 99-103. (In Russ.)

3. Guk AP. Principy fotogrammetricheskoj obrabotki metricheskoj informacii, poluchaemoj po aerokosmicheskim snimkam [The principles of photogrammetric processing of metric information obtained from aerospace images]. Interexpo Geo-Siberia, 2006;3; 2: 210-212. (In Russ.)

4. Guk AP., Antipov IT. Sovremennoe sostoyanie i perspektivnoe razvitie fotogrammetricheskih tekhnologij, distancionnyh metodov i monitoringa po aerokosmicheskoj informacii [Current state and future development of photogrammetric technologies, remote sensing methods and monitoring on aerospace information]. Interexpo Geo-Siberia, 2005; 5:3-5. (In Russ.)

5. Zlobin VK. Obrabotka aerokosmicheskih izobrazhenij: monografiya [Aerospace image processing: monograph]. M.: FIZMATLIT, 2006: 56-60. (In Russ.)

6. Makridenko LA. Distantsionnoe zondirovanie Zemli iz kosmosa I ustoichivoe razvitie obschetva [Distant sounding of the Earth from the space and stable development of the society]. Issues of electromechanics. RPC, 2008; 105: 4-5. (In Russ.)

7. Karpik AP. Razrabotka metodiki kachestvennoj i kolichestvennoj ocenki kadastrovoj informacii [Development of methods for the qualitative and quantitative assessment of cadastral information]. Publ.House Geodesy and aerial photography, 2013; 4: 137-138. (In Russ.)

8. Karpik AP. Analiz sostoyaniya i problemy geoinformacionnogo obespecheniya territorij [Analysis of the state and problems of geoinformation support of territories].University news. Geodesy and Aerophotography, 2014; 4: 3-7. (In Russ.)

9. Kosmicheskie apparaty s optiko-elektronnymi sistemami DZZ [Space vehicles with optico-electronic systems of remote sensing]. Geomatics, 2009; 1: 84-92. (In Russ.)

10. Kuznetsov SV., Usatin VZ. K voprosu o tekhnicheskom regulirovanii v sfere geodezii, kartografii i prostranstvennyh dannyh [To the Question of technical regulation in the field of geodesy, cartography and spatial data]. Geoprofi,2017; 8: 12-16. (In Russ.)

11. Labutina IA. Deshifrirovanie aerokosmicheskih snimkov: uchebnoe posobie dlya studentov vuzov [Interpretation of aerospace images: a textbook for university students, training. by special "Geography"]. M., Aspect Press, 2004: 62-66. (In Russ.)

12. Lisitsky DV. Osnovnye principy cifrovogo kartografirovaniya mestnosti [Basic principles of digital terrain mapping]. M ., Nedra, 1988: 264. (In Russ.) 
13. Parkhonenko IV. Informacionnaya model' gosudarstvennogo zemel'nogo nadzora [State land control of informational model]. University News, Geodesy and Aerophotography, 2015; 5: 90-96. (In Russ.)

14. Ovchinnikova NG., Shumkova ES. Uchetno-registracionnyj process v sisteme upravleniya zemel'nymi resursami [Accounting and registration process in the land management system]. Economy and ecology of territorial formations, 2016;2: 125-129. (In Russ.)

15. Russkikh AV., Ovchinnikova NG. Znachimost' dokumentov territorial'nogo planirovaniya municipal'nogo obrazovaniya dlya vedeniya EGRN [The importance of territorial planning of municipal formation for conducting EGRN]. Polythematic network Electronic journal "Scientific works Cube GTU", 2017; 4: 285 289. (In Russ.)

16. Sapelnikov SA., Tararin AM., Andreev AV. Kadastrovye karty municipal'nyh obrazovanij: balans vozmozhnostej i potrebnostej [Cadastral maps of municipalities: opportunities and needs balance]. Newsletter GIS Association, 2010, 4;76: 17-20. (In Russ.)

17. Sudarikov VN. Osnovy aerokosmofotos"yomki : uchebnoe posobie [Fundamentals of aerial photography: a training manul ].Orenburg,OSU, 2013: 230. (In Russ.)

18. Tararin AM., Rebry AV. Razvitie federal'nogo kartografo-geodezicheskogo fonda kak elementa infrastruktury prostranstvennyh dannyh [Development of federal cartography and geodesy fund as the part of a spatial data infrastructure]. Nizhniy Novgorod, Proceedings of Scientific and Technical Conference: Great Rivers, 2016:369-372. (In Russ.)

19. Tararin AM., Tararina EG. Normativno-pravovye i konceptual'nye aspekty formirovaniya kadastrovyh kart [Regulatory and conceptual aspects of the formation of cadastral maps]. Newsletter GIS Association, 2010; 4;76: 14-16. (In Russ.)

20. Tararin AM. Kartograficheskaya osnova kadastra: istoriya sozdaniya, celi i trebovaniya [Cartographic basis of the cadastre: the history of creation, goals and requirements]. Vestnik of SSUGiT, 2017; 22; 1: 137-138. (In Russ.)

Received 23.04.2020

Scheduled in the issue 15.05.2020

\section{Authors:}

Ovchinnikova, Natalya G., associate professor, the department of «Economics of Nature Management and Cadastre», Don State Technical University, (1, Gagarin Square, Rostov-on-Don, 344000, RF), associate professor, Ph.D. in Economics, donong160875@yandex.ru

Butova Anastasia Yu., student, the Department of «Environmental Economics and cadaster» Don State Technical University, (1, Gagarin Square, Rostov-on-Don, 344000, RF), 1 chinaski1@gmail.com 